\section{Platypnea-orthodeoxia-like syndrome in a septic newborn with late appearance of right congenital diaphragmatic hernia}

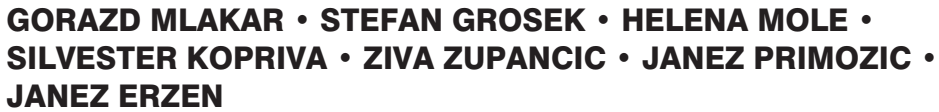

GORAZD MLAKAR - STEFAN GROSEK • HELENA MOLE • SILVESTER KOPRIVA • ZIVA ZUPANCIC • JANEZ PRIMOZIC • JANEZ ERZEN

STEFAN GROSEK $(\bowtie) \bullet$ GORAZD MLAKAR •

SILVESTER KOPRIVA • JANEZ PRIMOZIC

University Medical Centre Ljubljana Department of Paediatric Surgery and Intensive Care Bohoriceva 20 1525 Ljubljana, Slovenia Phone: +386 14301714

Fax: +386 14301714

E-mail: stefan.grosek@mf.uni-lj.si

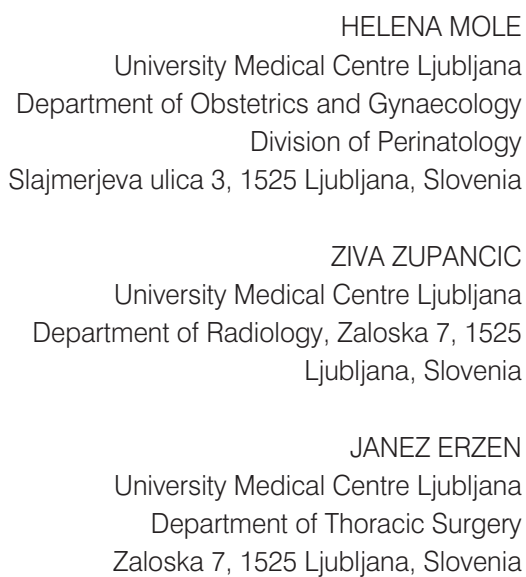

HELENA MOLE

University Medical Centre Ljubljana Department of Obstetrics and Gynaecology Division of Perinatology Slajmerjeva ulica 3, 1525 Ljubljana, Slovenia

ZIVA ZUPANCIC

University Medical Centre Ljubljana Department of Radiology, Zaloska 7, 1525

Ljubljana, Slovenia

JANEZ ERZEN

University Medical Centre Ljubljana Department of Thoracic Surgery Zaloska 7, 1525 Ljubljana, Slovenia

\begin{abstract}
Introduction. Cyanosis and dyspnoea with interatrial shunting of blood occurring without change in body position are termed platypnea-orthodeoxia-like syndrome.

Case presentation. We describe a female newborn with sepsis, who developed cyanosis. Two weeks after the initial appearance of cyanosis she presented with a right-sided diaphragmatic hernia, which was not seen on the initial X-rays. The hernia was surgically repaired. Her postoperative course was uneventful.

Conclusions. In our case, interatrial shunting of blood was presumably caused by disturbed intrathoracic pressures. Positive pressure ventilation and sepsis may also contribute to the development of such a syndrome.
\end{abstract}

Key words: cyanosis, right-to-left shunt, infant, sepsis, congenital diaphragmatic hernia

\section{Introduction}

The platypnea-orthodeoxia syndrome is a serious condition in which venous blood bypasses the lungs. (1) The dominant clinical signs are severe cyanosis and dyspnoea manifested in the upright position. Cyanosis and dyspnoea are relieved by assuming the recumbent position again. (2) Instances of cyanosis and dyspnoea occurring wit- hout the change in body position are termed the platypnea-orthodeoxia - like syndrome. (3)

Cases of platypnea-orthodeoxia and similar conditions in newborns with normal cardiac morphology have not been previously described in the literature.

\section{Case Report}

A female neonate, birth weight $2240 \mathrm{~g}$, body length $46 \mathrm{~cm}$, head circumference $32 \mathrm{~cm}$, was born to a healthy 41 -yearold woman (secundipara, quadrigravida) in the $346 / 7$ week of gestation after spontaneous rupture of membranes. The delivery itself was uncomplicated. Apgar scores were 9 / 9 at one and five minutes, respectively.

Two hours after birth she became cyanotic, tachypnoeic and required progressively higher concentrations of oxygen. She was intubated nine hours after birth. Conventional mechanical ventilation was initiated with $\mathrm{FiO}_{2}$ 1.0. Therapy with inhalation of nitric oxide (NO) 20 parts per million (ppm) was started immediately. The first chest film, taken after intubation, showed a reti- 


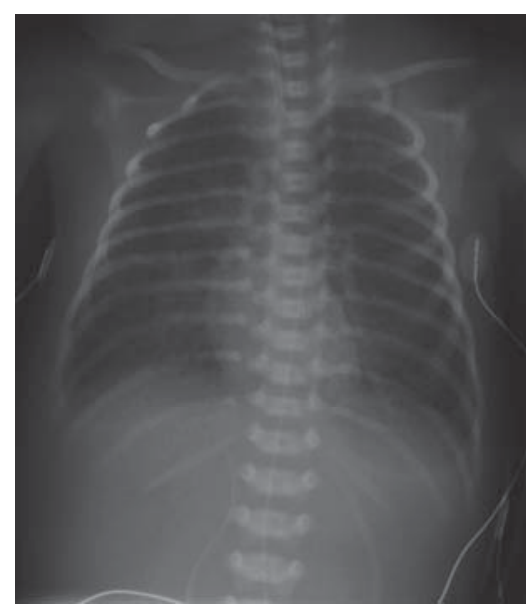

Figure 1. Radiograph taken at presentation of the right to left shunt demonstrates increased volume of lungs, bilateral diffusely increased interstitial markings, and tiny hyperlucencies throughout the lungs, which all give the appearance of diffuse interstitial emphysema. No signs of diaphragmatic hernia can be seen.

culogranular appearance of the lungs. She received two doses of the synthetic surfactant Curosurf $(100 \mathrm{mg} / \mathrm{kg}$ of body weight). Group B streptococci (GBS) were isolated from blood culture. She was placed on a regimen of ampicylin and gentamicin. Her mean arterial blood pressure was $33 \mathrm{mmHg}$ [4.39 $\mathrm{kPa}$, heart rate approximately 160 beats per minute and urine output 2.5 $\mathrm{ml} / \mathrm{kg} /$ hour. Blood oxygen saturation did not reach values above $90 \%$ despite a $\mathrm{FiO}_{2}$ of 1.0. The first ultrasound of the heart showed a structurally normal heart with signs of minor pulmonary valve insufficiency.

For the next two days she remained on $\mathrm{FiO}_{2}$ 1.0, with oxygen saturations between 80 to $90 \%$. She was hemodynamically stable, with good urine output $(2.8 \mathrm{ml} / \mathrm{kg} / \mathrm{h})$ and without inotropic support. On day four, arterial blood oxygen saturation dropped to below $80 \%$ on $\mathrm{FiO}_{2}$ 1.0, 20 ppm of nitric oxide, and controlled mechanical ventilation. She also became hemodynamically unstable. The lungs felt highly compliant on hand bagging. Because of profound hypoxemia, extracorporeal membrane oxygenation (ECMO) was

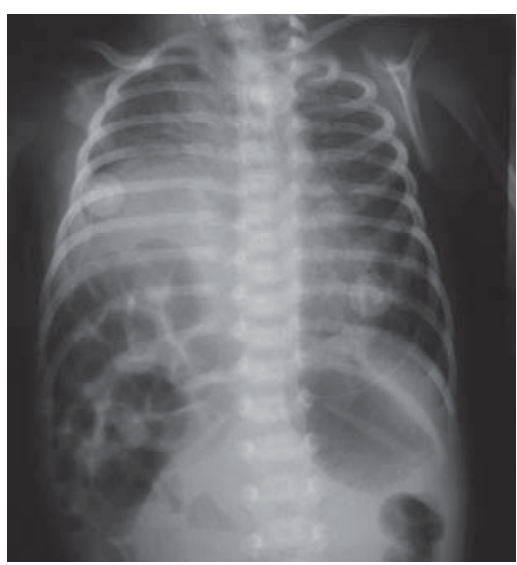

Figure 2. Radiograph taken during the final episode of respiratory failure shows consolidation in the lower part of the right hemithorax and a shift of the mediastinal structures to the left.

considered. She was transferred to the ECMO centre. Epinephrine and dopamine were started. Her circulatory condition temporarily improved. Ultrasound of the heart, performed by an experienced paediatric cardiologist, showed dominant interatrial right to left (R-L) shunting of blood streaming through a patent foramen ovale (PFO). The heart appeared otherwise normal, with good contractility of both ventricles and no signs of pulmonary artery hypertension (PAH). The chest film showed lungs with normally positioned right and left hemidiaphragms (figure1).

After admission to an ECMO centre, conventional ventilation on $\mathrm{FiO}_{2}$ 1.0, inotropes / vasopressors and prostaglandin E1, together with NO 20 ppm, were continued. Finally, complete reversal of the R-L shunt occurred, with rapid improvement in oxygenation and decreasing need for high $\mathrm{FiO}_{2}$. Subsequently her clinical condition improved within two days. Epinephrine and norepinephrine were withdrawn. She was extubated, with the post-extubation chest film appearing completely normal.

Two days after extubation she developed respiratory distress again, requiring intubation. The chest film at that time showed consolidation in the lower part of the right hemithorax and a shift of the mediastinal structures to the left (figure 2). A thoracotomy was performed. A congenital right-sided diaphragmatic hernia with herniation of the liver and a part of the small intestine was found. The defect was repaired with direct sutures. She remained mechanically ventilated for a further three days. The remainder of her hospital stay was entirely uneventful.

\section{Discussion}

Severe cyanosis and dyspnoea are relatively common in neonates with respiratory distress syndrome. $(4,5)$ The culprit for this cyanosis is $\mathrm{PAH}$ and right-to-left shunting of blood through a PFO and ductus arteriosus (PDA) secondary to $\mathrm{PAH}$. Cases of right-toleft blood shunting without pulmonary hypertension are virtually unknown in neonates.

In adults R-L interatrial shunting without $\mathrm{PAH}$ or normal intracardiac pressures has been reported in platypnea-orthodeoxia syndrome. (1) The interatrial shunting of blood in platypneaorthodeoxia syndrome is thought to arise because of a pressure gradient between the right and left atrium, usually caused by compression of the right side of the heart by adjacent masses. $(6,7)$ A right-to-left interatrial shunt may exist even in the absence of a pressure gradient. Godart et al. proposed that an abnormal spatial relationship between the inferior vena cava and the interatrial septum exists over the PFO, causing a jet of blood from the inferior vena cava to flow directly through the foramen ovale into the left atrium in patients after right-sided pneumonectomy or eventration of the right hemidiaphragm. (8) Recently, Pavoni et al. described a similar condition, a transient platypnea-orthodeoxia-like syndrome in a young woman with Ebstein's anomaly in whom the precipitous cause of profound hypoxemia and cyanosis was intoxication with propafenone. (3) Only one fatal case of a transient platypneaorthodeoxia-like syndrome (called cyanotic atrial septal defect by the authors) with R-L interatrial shunting without 
$\mathrm{PAH}$ in a premature infant has previously been reported in the literature. (9) In our case, we hypothesized that the right-sided congenital diaphragmatic hernia may have changed the spatial relationship between the inferior vena cava and the PFO or increased the pressure on the right heart. This may have resulted in a jet of blood from the inferior vena cava streaming directly through the PFO into the left atrium. To our knowledge this is the first description of $\mathrm{R}-\mathrm{L}$ shunting without $\mathrm{PAH}$ (a transient platypnea-orthodeoxia-like syndrome in a newborn) in a severely hypoxemic and cyanotic neonate with a right-sided congenital diaphragmatic hernia without herniation and sepsis.

\section{Conclusions}

Platypnea-orthodeoxia-like syndrome with right-to-left shunting through a PFO without $\mathrm{PAH}$ and with profound hypoxemia is a life-threatening condition. A right-sided congenital diaphragmatic hernia together with sepsis and positive pressure ventilation might explain this severe cyanosis and hypoxemia.

\section{REFERENCES}

1. Burchell HB, Helmholz HF Jr, Wood EH. Reflex orthostatic dyspnea associated with pulmonary hypertension. Am J Physiol 1949;159:563-4.

2. Suzuki $H$, Ohuchi $H$, Hiraumi $Y$, Yasuda K, Echigo S. Effects of postural change on oxygen saturation and respiration in patients after the Fontan operation: Platypnea and orthodeoxia. Int J Cardiol 2006;106(2):211-7.

3. Pavoni D, Ragazzo S, Driussi M, Antonini-Canterin F, Pavan D, Zardo F, et al. Transient platypnea-orthodeoxia-like syndrome induced by propafenone overdose in a young woman with Ebstein's anomaly. Ital Heart J 2003;4(12):891-4.

4. Walther FJ, Benders MJ, Leighton JO. Persistent pulmonary hypertension in premature neonates with severe respiratory distress syndrome. Pediatrics 1992; 90:899-904.

5. Abman SH. Neonatal pulmonary hypertension: a physiologic approach to treatment. Pediatr Pulmonol Suppl 2004;26:127-8.

6. Sorrentino M, Resenkov L. Patent foramen ovale associated with platypnea and orthodeoxia Chest 1991;100(4):1157-8.

7. Bakris NC, Siddiqi AJ, Fraser CD, Mehta AC. Right-to-left interatrial shunt after pneumonectomy. Ann Thorac Surg 1997;63:198-201.

8. Godart F, Rey C, Prat A, Vincentelli A, Chmal"t A, Francart C, et al. Atrial right-to-left shunting causing severe hypoxemia despite normal right-sided pressures. Eur Heart J 2000;21:483-9

9. Chong YM, So LY, Fok TF, Gerlis LM. Cyanotic atrial septal defect in a premature infant. Pediatr Cardiol 1991;12(1):63. 